\title{
An Assessment of the Translations of English Lyrics in World's Six Different Music Style Based on Hurtado's Model of Error Analysis
}

\author{
ShimaKhabir ${ }^{1, *}$, Mohammad Reza Falahati Qadimi Fumani ${ }^{2}$ \\ ${ }^{1}$ Department of Translation Studies, Science and Research, Branch, Islamic Azad University, Fars, Iran \\ ${ }^{2}$ Department of Computational Linguistics, Regional Information Center for Science and Technology, Shiraz, Iran \\ *Corresponding Author: shima.khabir@yahoo.com
}

Copyright (C) 2013 Horizon Research Publishing All rights reserved.

\begin{abstract}
The present study aimed to investigate the qualities of Persian translated lyrics originally written in English. In this regard, one-hundred and twenty lyrics out of six music styles (pop, rap, jazz, Latin, metal and rock) were chosen through purposive sampling to be studied. To begin with, each of the lyrics was carefully compared to their corresponding Persian translations in search for any erroneous renderings made while being translated. The researcher used Hurtado's (1995) model of translation error analysis, containing three main categories including 'translation mistakes', 'translation major errors' and 'translation minor errors'. Each of these categories was then given the negative points of 2,1 , and 0.5 to be subtracted respectively. What remained were pieces of translated lyrics graded out of 100 . The next step involved the act of calculating the mean scores of each music styles. Finally, a Chi-Square test was applied to see whether the differences among the mean scores relating to each music style were of any statistically significance or not. The results of the study revealed no statistically significant differences among the qualities of the Persian translated lyrics with an insight form the six afore-mentioned music styles.
\end{abstract}

Keywords Translation Quality Assessment, Lyrics Translation, Music Styles, Error Analysis, Hurtado

\section{Introduction}

Translation Studies (TS), since its emergence as a discipline (Munday, 2008), has attracted scores of researchers and scholars. Given the volume of research already undertaken, comparative research has proved a prominent field of study. In such research, a Source Text (ST) is compared with its Target Text (TT) by means of relevant translation models. According to Munday (2008, p. 10), "The main aim of these studies could be examining the existing translations."Chesterman (2007) points out that the main aim of conducting a comparative study might be showing the relationship between a translated text and other texts. These texts may include:

- Source texts (in order to show the equivalence relation);

- Non-translated comparable texts in the target language (in order to work on the naturalness relation);

- Other translations (forin order to conduct research on translation universals); or

- Non-native texts.

Catford's (1965) model of translation shift typology, Koller's (1979) work on equivalence and Vinay andDarbelnet's (1958) model of translation strategies are only some examples of comparative translation models designed to undertake comparative studies. Studies carried out based on contrastive research and corpus-based work on translation universals areamong other instances of comparative research. Catford's (1965) model, for instance, is based on the analysis of different relation types holding between STs and their corresponding translations, his theory of equivalence and finally his classification of shift types. An equivalence typology also lies at the center of Koller's (1979) model, who distinguishes denotative, connotative, text-type, pragmatic and formal types of equivalence.

Despite all the previous studies already undertaken, the question still remains as to whether there exists a significant gap between the translations produced for different publication purposes. As Reiss and Vermeer (1984) believe, all translations have a specific purpose and only by having that final aim or purpose in mind, the appropriate translation procedures must be chosen.Lyrics, on the other hand, have been evolving gradually during the past in terms of their dynamics, contents, styles and all other elements involved. In addition, this seems to be true within different music styles, as the purpose, audience and performers of these styles differ in their ideology, race, power, etc. (Van Dijk, 
1995).

The total number of book publications in Iranian society has been astronomical. A great proportion of such books published in an array of different languages like Arabic, Italian, Russian, French, etc. but mostly in English, since this latter language is often deemed as lingua franca - have bilinguals as their potential target readers. These books enjoy different aims and scopes, literary genre being only one example. English poetry, in general, and lyrics, in particular, received much attention in Iran in 1990s. Scores of lyrics were translated from English into Persian during that time. Thus, as a tool to a better understanding of the translation phenomenon, the present study aimed at investigating the Translation Quality Assessment (TQA) related issues of nine English lyrics publications translated into Persian using Hurtado's (1995) model of error analysis. To attain the above broad objective, the following research question was introduced:

Are there any statistically significant differences between the qualities of translated English lyrics into Persian in different western music styles based on Hurtado's (1995) model of error analysis?

\section{Review of the Related Literature}

Comparative studies have been undertaken abundantly over the globe (Cohen, Manion\& Morrison, 2007). The bulky volume of research in comparative studies could well be justified by the availability of different dynamics and potentialities in world languages. In what follows the literature closely related to the topic of the present research is reviewed.

\subsection{Theoretical Considerations}

TQA is known to be a fast growing sub-field in TS (Williams, 2004). It focuses on the inter-relationships between the text translated from ST and the one translated into TT. Theseinter-relationships involve lexis, grammar, syntax, and semanticsof the source and the target texts. Unlike sentences in isolation, texts are context-bound and thus a distinction between text and sentence is made. Further, text-boundtranslation can only be conducted and assessed within the domain oftext-linguistics (ibid.).

TS theorists and critics have always been in favor of assessing the quality of a translated work. The term TQA basically roots in the notion of evaluation. As Scriven (1993, p. 1) points out, evaluation is "...the determination of merit, worth or significance". In other words, it would be the main purpose of TQA to assess a piece of translation as 'weak' or 'good'.

Assessment of a translated text's quality should be based on a definable,applicable, and testable model which, in turn, should be based on acomprehensive theory of translation (Williams, 2004).Current models for translation emphasize one aspect against others. For instance, the grammatical model focuses on the linguistic aspect of translation. The cultural model, on the other hand, highlights the communicativeaspect whereas the interpretive model concentrates on the pragmaticaspect of translation. Such artificial compartmentalization is aliento the nature of translation. As a process, translationinvolves the integrated synthesis of the above aspects.As Williams (2009) points out, TQA could be "...qualitative or quantitative, just like evaluation in the broad sense: It can be based on mathematical or statistical measurements or on reader response, interviews and questionnaires" (p. 2).

With respect to all the various models of TQA available these days, the ST and the TT are yet to hold a high degree of importance. That is, the translation process concerning lyrics could be way more complicated one, compared to a scientific informative text. Hence, the process of TQA would be a complicated one. In his "Translation Quality Assessment", Williams $(2009$, p. 3$)$ refers to the most important elements to be taken into consideration while dealing with TQA. These items include "the evaluator", "level of target language rigor", "seriousness of errors of transfer", "sampling versus full-text analysis", "quantification of quality", "levels of seriousness of errors", "multiple levels of assessment" and "TQA purpose/function".

The first step towards lyric translation assessment is to come up with a theory of poetry translation. One would be in favor of Jakobson's (1959/2004) ideas who believes poetry and lyrics are totally untranslatable or support Nabokov's (as cited in Baker, 1998) theory insisting that the only legitimate method for translating poetry and lyrics is a literal translation, while others may apply a moderate viewpoint like the one introduced by Baker (1998):

The view that it is impossible to translate poetry recognizes that it is impossible to account for all the factors involved and to convey all the features of the original in a language and form acceptable to the target language culture and tradition (p. 171).

\subsection{Models of TQA}

There have been many attempts to build a model for evaluating the quality of a translated work. TQA studies, according to House (1998), can be divided into three major categories: 1) there are pre-linguistic studies, in which subjective and not-so-much clear statements, regarding the quality of a translated work, are the major trend. 2) There are psycholinguistic studies. In these studies translation quality is judged in terms of the effect a translation should have on the readership, and 3) there are source-text based studies which attempt to build linguistic criteria to account both for the ST and the TT.

In the literature, there have also been pragmatic models, too. Williams (2004) dividedTQA models into two main types: 1) models with a quantitative dimension and 2) non-quantitative, text-logical models, such as House's (1998) models of TQA.

Among translation issues, lyric translation has always 
tended to be among the most problematic areas challenging both translators and their authorities while making the act of rendering from one language into another. That is why Francis (2006, p. 23) calls the act of such translation a "yet unanalyzed black box". Different researchers, scholars and theorists have already made great strides to compromise on a systematic model of poetry TQA, but to no avail. In fact, the large scope of this research domain has made this objective far-reaching.

Unlike lyrics, poetry translation seems to enjoy a longer background in Iran. VahidDastjerdi, Hakimshafaaii and Jannesaari (2008) compared a piece of translated English poetry with its original Persian one. The findings were then descriptively analyzed at both linguistic and extra-linguistic levels. The results indicated that there were some difficulties and unresolved issues while assessing poetry translations. They also proposed a detailed model concerning this complicated act.

\subsection{Empirical Background}

Applying VahidDastjerdi et al.'s (2008) model, Jamshidian and Mohammadi (2012) studied a Persian piece of poetry by Moshiri and its English rendering by VahidDastjerdi in order to examine the closeness of TT to the original text in terms of grammar and poetics. The results of the study indicated that such issues as literary expertise, background knowledge and cultural knowledge were dominant features in the success of a translator while translating literature and poetry, in particular, at a global extra-textual level.

Using VahidDastjerdi et al.'s (2008) model, Shafieie and Hatam (2009) presented an English translation of a Persian piece of modern poetry in order to assess the translator's performance in preserving the form and the content of the original poem in terms of this product-oriented model for translation analysis. The two texts were analyzed at both textual (linguistic) and extra-textual (cultural) levels and the results obtained were used to assess the poetic discourse.

In addition to the aforementioned studies and many more undertaken previously, a lot are yet to be conducted in order to delve into different aspects and perspectives in TQA of literary, in general, and lyrics, in particular.Barghout (1990) presented a model of translation quality assessmentbased on a sound theory of translation which comprehended thephilosophical (pragmatic), communicative (cross-cultural), and semiotic (linguistic) aspects of language. Since translation is a semantic entity, this model, labeled as "rhetorical" focused on the concept of "meaning shifts" according to which the meaning of a text isclassifiable into obligatory, extended, and accessory meanings. This did not suggest that the semantic structures of a text exist in a state of utter un-relatedness. As a conclusion, he classified texts broadly intoliterary, non-literary, and hybrid providing each one with a brief definition (ibid.). Although the model in question was primarily designed for TQA, it hadsome pedagogical implications as well. As Baghout (1990) posited, translation students and trainees could implement this model in textual analysis before theyembarked on the process of translation. Phonological, grammatical,syntactic, semantic, and lexical correspondences between SL and TL texts were identified before assessing the translation quality.

Sharkas (2009) examinedtranslation problems that popular science featurearticles, as a genre, posed for translators. She also investigated the methods followed tohandle theseproblems and, of course, their ability to produce adequate translations. The method of her analysis was the onein which the principle of translation loss was drawn on to assess the adequacy of a target text in relation to five textual levels - i.e. genre, cultural, semantic, formal and varietal. The model also took the translation brief andgenre characteristics into account during the assessment process. A working hypothesis andfour sub-hypotheses were developed to perform this investigation. Textual analysis identifiedseveral translation problems, some of which were general and some specific to the genre.The results also revealed that the methods followed by translators varied. The analysis further showed that translation loss was mainly onthe semantic and formal levels.

In another study, Mohaghegh (2011) made an attempt to apply a text-based approach of translation criticismproposed by Reiss (2000) to examine Clarke's (1891) English translation of Ghazal No.167 of Hafez by focusingon evaluation of linguistic elements consisting of four parts. Comparing the original Persian poem with itstranslation, the researcher came up with the conclusion that at linguistic level, there were anumber of cases in which the translator's miss-reading of the original poem had led to the miss-translation and due to a literal rendering, some idioms had been translated un-intelligibly.

In their comparative study, Yamini and Abdi (2009) aimed at detailed investigation of House's (1998)TQA model and its potential power to predict the errors in Persian translations of literary works. In this regard, a Persian translation of William Shakespeare's Macbeth on the basis of House's (1998) TQA model was undertaken. Having introduced the model, definitions and different stages of the assessment process, the researcher randomly selected some samples of ST and TT and analyzed them. First, the errors were identified and classified. Then, the frequency of their occurrences was computed to see whether a statistically significant difference could be found. Finally, a Chi-Square statistical procedure was employed to compute differences between observed and expected frequencies of the errors which were categorized into "covertly erroneous errors" and "overtly erroneous errors". Overtly erroneous errors were further categorized into five categories: 1) Not Translated; 2) Slight Change in Meaning; 3) Significant Change in Meaning; 4) Distortion of Meaning; and 5) Breach of the Target Language System. The results of their Chi-Square statistical procedure indicated a statistically significant difference between the two kinds of errors and among the five types of overtly erroneous errors. Therefore, this particular piece of translation did not comply with the 
hypothesis "a literary work, according to House's (1998) model, has to be translated overtly and any deviation of it will be considered as an error".

Considering the related literature, the gap existing within the realm of lyric translation could be felt in a more tangible perspective. In other words, several elements have possible impacts on the quality of a translated lyric, as discussed before. Thus, the present study aimed to investigate these issues, using the introduced method.

\section{Research Aides}

A number of people helped the present researcher during data collection and analysis as follows:

- A graduate student of English Translator Training, M.A. level, double checked the accuracy of the data collected. During data analysis, he also analyzed the data, along with the present researcher, and undertook the rating.

- An expert with a Ph.D. degree in Translation also helped by commenting when the two raters, the present researcher and the graduate student of English Translator Training, M.A. level, were not able to resolve their differences or come up with the same judgment or decision. The final decision was based on his judgment.

\section{Materials}

The materials and data sources drawn on in the present study were as follows:

- Nine publications of English lyrics translated into Persian. These included "The Sad Eyes" By Mahmoudinejaad (2003), "One Broken Heart for Sale" by GohariRaad (2004), "On the Wings of Night" by Kiaan (2003), "Victory" by Houshmandi (2003), "Eminem" by Qorbaanzaade (2003), "Mega-death" by Jamaali\&Mohaqeq (2003), "Black and Blue" by Sanaajian (2002), "Latino Soul" by Kiaan (ibid.) and "To the Shores of Dream" by Nourizaade (2000).

- Twenty lyrics from six different music styles chosen through purposive sampling. These lyrics were chosen form the nine afore-mentioned publications, leading to the total number of one-hundred and twenty lyrics.

- Hurtado's (1995) model of error analysis, in which an ST is compared with its corresponding TT to assess the quality of a piece of translation. Two main terms in this model include translation mistakes and translation errors the latter being further divided into major and minor errors. Translation mistakes refer to inappropriate renderings which affect the understanding of the source text; these are divided into eight categories: countersense, false sense, nonsense, addition, omission, unresolved extra-linguistic references, loss of meaning, and inappropriate linguistic variation (register, style, dialect, etc.). Translation major errors refer to inappropriate renderings which affect expression in the target language; these are divided into five categories: spelling, grammar, lexical items, text and style. Finally, translation minor errors refer to inadequate renderings which affect the transmission of either the main function or secondary functions of the source text.

\section{Data Collection Procedure}

First, nine publications of English lyrics translated into Persian were selected through purposive sampling. Then, twenty lyrics out of each music style were selected through the process of purposive sampling from the nine publications. However, these lyrics might face an overlap with one another in some cases. Then, each and every lyric was compared with its corresponding translation in the nine afore-mentioned publications and later analyzed using Hurtado's(1995) model of error analysis.

\section{The Scoring System}

To assess the quality of the translations made, the following scoring system was drawn on:

Table 1. The Scoring System Used

\begin{tabular}{|c|l|c|}
\hline \multicolumn{2}{|c|}{ Mistake/Error Type } & Point(s) to be Subtracted \\
\hline \multicolumn{2}{|c|}{ Translation Mistake } & -2 \\
\hline \multirow{3}{*}{ Translation Error } & Major Error & -1 \\
\cline { 2 - 3 } & Minor Error & -0.5 \\
\hline
\end{tabular}

As indicated in Table 1., each and every item denoting a problem in the translation was given a negative point: -0.5 (for minor errors), -1 (for major errors) and -2 (for translation mistakes). Then, all the scores calculated for the items, in each translation, were put together to compute the total score of the work out of 100. Later, the ratings from the twenty graded translations, from each of the six music styles, were used as input data to undertake statistical analysis.

\section{The Question of Reliability}

Inter-rater reliability gives a score of how much consensus there is in the ratings given by the judges. In this study, two judges - the present researcher as well as a graduate student of English Translator Training, M.A. level, analyzed the data and undertook the rating. When the ratings of the two raters were the same, theywere recorded as such; otherwise, they 
further discussed the case and the result they came up with, through the compromise, was judged as reflecting the views of both raters. When the two raters could not reach an agreement, a Ph.D. holder in Translation commented on the issue the opinion of whom was used as final rating.

\section{Procedure of the Study}

To undertake the study, the following steps were taken: First, nine publications of English lyrics translated into Persian were selectedthrough purposive sampling. Then, these lyrics were compared to their corresponding translations in search for any 1) translation mistakes, 2) translation major errors and, 3) translation minor errors. In fact, Hurtado's (1995) model of error analysis was used as the basic framework of the present work. The next step involved the act of scoring each translated lyric out of 100 . Finally, the mean scores of the six music styles were compared to one another in search for any statistically significant differences in terms of the qualities of their translations.

\section{Results and Discussion}

As it was mentioned before, the framework used within the present study was based on Hurtado's (1995) model of error analysis. This was to assess the qualities of Persian translations of one-hundred lyrics, originally written in English. In this regard, the lyrics were chosen and thus ready to be studied. First, each and every lyric was carefully compared to its corresponding Persian translation. Then, using Hurtado's (ibid.) model, the erroneous cases were highlighted. These included a) translation mistakes, b) translation major errors, and c) translation minor errors. Each of these categories held some sub-divisions by themselves. Then, each of the cases were given a negative point ( -2 for translation mistakes, -1 for translation major errors and -0.5 for translation minor errors) during the research process. The final remaining grade was observed out of 100 . In addition, the music styles were taken into account, too. In fact, there were mainly six music styles, consisting twenty lyrics in each.

Table 2. A Demographic Overview of the Mean Scores Obtained Concerning the Six different Music Styles Investigated

\begin{tabular}{|c|c|}
\hline Name of the Music Style Investigated & The Mean Scores Obtained \\
\hline Jazz & 95 \\
\hline Rap & 86 \\
\hline Pop & 94 \\
\hline Rock & 100 \\
\hline Metal & 90 \\
\hline Latin & 100 \\
\hline Total & $\mathbf{5 6 5}$ \\
\hline
\end{tabular}

The next step involved the act of achieving a certain grade for each of the six afore-mentioned music styles. In doing so, the final grades of the translations were summed up and then the mean score of them were calculated. Table 2. provides a demographic overview of the mean scores obtained, concerning the six different music styles.

On Table 2, it is important to mention that all the available versions of SPSS (the $16^{\text {th }}$ version was used within the present work) automatically round the numbers in order to have a more readable piece of result. In addition, this might seem interesting to note that the mean score for all of the six music styles were more than 85 .

To see whether the differences among the six afore-mentioned music styles held any statistically significant differences or not, a Chi-Square test was applied. This was done using the $16^{\text {th }}$ version of SPSS software, as mentioned before. Table 3. gives some basic information on the data input, concerning the mean scores of the music styles obtained:

Table 3. Some Information on the Basic Input of the Six Different Music Styles Mean Scores Obtained

\begin{tabular}{|c|c|c|c|}
\hline Music Styles & Observed N & Expected N & residual \\
\hline Jazz & 95 & 94.2 & .8 \\
\hline Rap & 86 & 94.2 & -8.2 \\
\hline Pop & 94 & 94.2 & -.2 \\
\hline Rock & 100 & 94.2 & 5.8 \\
\hline Metal & 90 & 94.2 & -4.2 \\
\hline Latin & 100 & 94.2 & 5.8 \\
\hline Total & 565 & & \\
\hline
\end{tabular}

Accordingly, Figure 1. illustrates the differences obtained among the mean scores of the Persian translated lyrics:

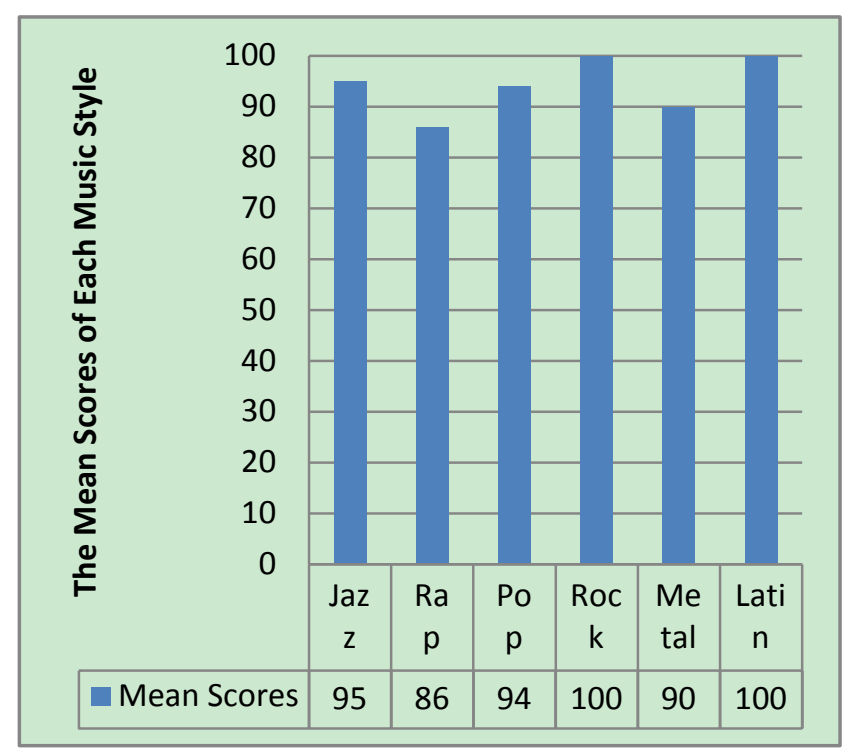

Figure 1. The Differences Among the Mean Scores of the Six Music Styles 
To make sure whether the differences among the six music styles studied held any statistically significant differences or not, a Chi-Square test was done, the result of which is presented in Table 4, as follows:

Table 4. The results of the Chi-Square Test on the Meaningfulness of the Differences Among the Mean Scores of the Six Music Styles Under Study

\begin{tabular}{|c|c|}
\hline Chi-Square & 1.623 \\
\hline $\mathrm{df}$ & 5 \\
\hline Asymp. Sig. & .898 \\
\hline
\end{tabular}

Concerning the results of the Chi-Square test, there were no statistically significant differences between the qualities of the Persian translated lyrics originally written in English.

As the introductory part of this section, the researcher would like to re-present the posed research question as follows:

Are there any statistically significant differences between the qualities of translated English lyrics into Persian in different western music styles based on Hurtado's (1995) model of error analysis?

As the results of the Chi-Square test revealed, there were no statistically significant differences among the qualities of the translated versions of English lyrics while rendered into Persian. In this regard, a series of reasons might be taken into consideration.

While dealing with the act of translation, the translator tends to give the best work one would be able to do. Thus, a numerous number of investigations, aids and tools of translation will be applied in order to achieve an acceptable piece of translated text (Larson, 1998).

Due to cultural reasons, most of the translators enjoy similar criteria while dealing with the act of translation (Chesterman, 2009). Not only true for Iranian translators, this could be regarded as a global act. This is to support the existence of the universals of translation.

Nearly all of the translators' mother tongue was Persian. Thus, it could be possibly stated that the features and characteristics of that language could have a possible effect on the final translations carried out by them (Newmark, 1988).

\section{Conclusion}

The present study held a sort of innovative framework, purpose and methodology, to the best knowing of the researcher. This is mainly because the roles of music styles on the qualities of translated lyrics have often been neglected. In other words, as discussed in before, the music style of a certain pieces of lyric could have possible impacts on the several different related aspects of that lyric. For instance, the rap style enjoys larger segments, referred to as 'texts', rather than lyrics. Accordingly, the feeling they convey might differ due to several known and unknown reasons, ranging from literature to psychology.
Another important issue left to be mentioned relates to the translations of the lyrics with the music styles achieving the highest grades during the process of data analysis. Out of the six music styles studied, only two of them turned out to achieve the total grade out of 100 . There might be a series of reason discussed within the following sections.

Concerning the Latin style, the translations were of a good quality. This might be related to the fact that these lyrics usually tend to use a rather simple language style, as related to the nature of their mother language, although the lyrics investigated were written in English. On the other hand, concerning the rock style, this is a music style which holds the orientations towards using shorter segments of lyrics. This might be related to the nature of the music.

The results of the present work revealed no statistically significant differences between the qualities of the Persian translated versions of English lyrics. A series of possible reasons in terms of this phenomenon were pointed out in accordingly. Concerning those reasons discussed previously, one cannot argue that the qualities of the translated versions of lyrics with reference to different music styles hold any statistically significant difference.

\section{REFERENCES}

[1] Baker, M. (1998). Routledge encyclopedia of translation studies. London: Routledge.

[2] Barghout, M. A. M. (1990). Translation quality assessment: An application of a rhetorical model, PhD thesis, University of Salford, UK.

[3] Catford, J. C. (1965/2000) A Linguistic Theory of Translation, London: Oxford University Press (1965).

[4] Chesterman, A. (2009). The name and nature of Translator Studies. Hermes - Journal of Language and Communication Studies, 42 (15).

[5] Clarke, H. (1891). The divan, written in the fourteenth century. New York: Samuel Weiser INC.

[6] Cohen, L., Manion, L., \& Morrison, K. (2007). Research methods in education (6th Ed.). Washington DC: Taylor \& Francis.

[7] Francis, R. 2006. Unlocking the Black Box: Researching Poetry Translation Processes. In M. Perteghella\& E. Loffredo (eds.), Translation and Creativity 59. London: Continiuum.

[8] GohariRaad., H. (2004). one broken heart for sale. Teahran: Dej.

[9] House, J. (1998). Quality of translation, In M. Baker, (Ed.), Routledge Encyclopedia of Translation Studies, London:Routledge.

[10] Houshmandi, H. (2003). Victory. Teahran: Afkar.

[11] HurtadoAlbir, A. (1995): "La didáctica de la traducción. Evolución y estado actual," X Perspectivas de la Traducción, (P. Fernández, ed.), Valladolid, Universidad de Valladolid, 
pp.49-74.

[12] Jakobson, R. (1959/2004). On linguistic aspects of translation, In L. Venuti (Ed.), The Translation Studies Reader, pp.113118, London: Routledge.

[13] Jamali, B., \&Mohaqeq, N. (2003). Mega-death. Teahran: Peyk-e-Adabiat.

[14] Jamshidian, E., \&Mohammadi, R. (2012). Translation Analysis and Assessment of Poetic Discourse: Extra-textual Meaning in Persian and English. The Journal of International Social Research, 5(21), pp. 1-10.

[15] Kian, V. (2003). Latino soul. Tehran: Andishe-ye-Aalam. (2003). On the wings of night. Tehran: Andishe-ye-Aalam.

[16] Koller, W. (1979) Einführung in Übersetzungswissenschaft, Heidelberg Wiesbaden: Quelle und Meyer. Lanham, Md.: University Press of America.

[17] Mahmoudinejad, H. (2003). The sad eyes. Teahran: Shaad.

[18] Munday, J. (2008). Introducing translation studies: Theories and applications (2nd Ed.). London: Routledge.

[19] Nourizade, A. (2000). to the shores of dream. Tehran: Aatie.

[20] Qorbanzade, M. (2003). Eminem. Tehran: Afkar.

[21] Reiss, K. (2000). Translation criticism: The potentials and limitations, categories and criteria for translation quality assessment, translated by Eroll F. Rhodes. Manchester, UK: St. Jerome.

[22] Reiss, K., \& Vermeer, H. J. (1984). Grundlegungeinerallgem einenTranslationstheorie. Tul``bingen: M. Niemeyer.
[23] Sanajian, N. (2003). Black and blue. Teahran: Afkar.

[24] Scriven, M. (1993). Hard-won Lessons in Program Evaluation. San Francisco: Fossey-Blass.

[25] Sharkas, H. (2009). Translation quality assessment of popular science articles: corpus study of the scientific American and its Arabic version. Trans-kom, 2 (1), pp.42-62.

[26] VahidDastjerdi, H. ., Hakimshafaaii, H., \&Jannesaari, Z. (2008). Translation of Poetry: Towards a Practical Model for Translation Analysis and Assessment of Poetic Discourse. Journal of Language and translation, 9(1), 7-40. Retrieved November 20, 2012, from http://www.unish.org/upload/wor d/911.pdf

[27] Van Dijk, T. A. (1995). Discourse analysis as ideology analysis. Language and pace, pp. 17-33. Aldershot: Dartmouth Publishing.

[28] Vinay, J. P. and J. Darbelnet (1958, 2nd edition 1977) Stylistiquecomparée du français et de l'anglais:Méthode de traduction, Paris: Didier, translated and edited by J. C. Sager and M. J. Hamel (1995) as Comparative Stylistics of French andEnglish: A Methodology for Translation, Amsterdam and Philadelphia, PA: John Benjamins.

[29] Waddington, C. (2001). Different Methods of Evaluating Student Translations: The Question of Validity. Eurodite, 46(2), 311-325.

[30] Williams, M. (2004). Translation quality assessment: An argumentation-centered approach. Ottawa: University of Ottawa Press. (2009). Translation quality assessment. Meta, 17(2). 